Abant Tıp Dergisi

Araştırma Makalesi / Cilt 10 Sayı 1 Yıl 2021
Abant Medical Journal

Research Article / Volume 10 Issue 1 Year 2021

\title{
Fournier Gangreninde Cerrahi Tedavi Sonuçlarımız: Tek Merkez Deneyimi
}

\section{Our Surgical Treatment Results in Fournier's Gangrene: A Single Center Experience}

\author{
Serkan ERKAN ID , Hakan YABANOĞLU iD, Ramazan GÜNDOĞDU iD, Murat KUŞ iD
}

Başkent Üniversitesi Dr. Turgut Noyan EAH. Genel Cerrahi Kliniği Adana, Türkiye

Öz

GíRiş ve AMAÇ: Fournier Gangreni (FG) ürogenital sistem, anorektal bölge ve genital deri enfeksiyonlarının sonucu olarak ortaya çıkan nadir bir durumdur. Bu çalışmada FG nedeniyle ameliyat edilen hastaların sonuçlarını sunmayı amaçladık.

YÖNTEM ve GEREÇLER: Merkezimizde Ocak 2010-Ağustos 2020 tarihleri arasında FG nedeniyle takip ve tedavi edilen hastaların dosyaları geriye dönük incelendi. Çalışma kriterlerine uyan 59 hasta çalışmaya dahil edildi. Hastaların klinik değerlendirilmesinde Fournier Gangreni Şiddet indexi (FGSI) ve Uludağ Fournier Gangreni Şiddet Indexi (UFGSI) kullanıldı.

BULGULAR: Hastaların $18(\% 30,5)^{\prime}$ i kadın, $41(\% 69,4)^{\prime}$ i erkek idi. Yaş ortalaması $60(34-87)$ yıl idi. Hastaların 25 $(\% 42,3)^{\prime}$ inde skrotal, 27 (\%45.7)' sinde perianal, 7 $(\% 11,8)^{\prime}$ inde vulvar hastalık bulgusu mevcuttu. Ortalama debridman sayısı 3,4 (1-13) idi. Hastaların 16 (\%27,1)' ına kolostomi, 6 (\%10)' ına orşiektomi işlemi yapıldı. Onsekiz hastaya $(\% 30,5)$ Vakum Aspirasyonlu Kapama (VAK) uygulaması yapıldı. Hastanede ortalama yatış süresi 15.4 (160) gün idi. Hastaların ortalama FGSI skoru 4,16 (1-14), UFGSI skorları 5,05 (1-16) idi. Mortalite oranımız \%16,9 idi. TARTIŞMA ve SONUÇ: Fournier Gangreni tanısında erken tanı çok önemlidir. Erken tanı ile birlikte gerekli cerrahi debridman, diversiyon işlemleri ve geniş spektrumlu antibiyotik uygulamaları tedavi başarı oranını arttırmaktadır.

Anahtar Kelimeler: Fournier gangreni, debridman, kolostomi, diabetes mellitus

\section{Abstract}

INTRODUCTION: Fournier's Gangrene (FG) is a rare condition that occurs as a result of infections of the urogenital tract, anorectal region, and genital skin. In this study, we aimed to present the clinical results of patients operated on for FG.

METHODS: We retrospectively reviewed the files of patients who were followed up and treated for FG between January 2010 and August 2020 in our center. 59 patients who met the study criteria were included in the study. Fournier's Gangrene Severity Index (FGSI) and Uludağ Fournier's Gangrene Severity Index (UFGSI) were used for clinical evaluation of the patients.

RESULTS: Eighteen (30.5\%) of the patients were female and $41(69.4 \%)$ were male. The average age was 60 (34-87) years. Scrotal disease in $25(42.3 \%)$ patients, perianal disease in $27(45.7 \%)$, and findings of vulvar disease in 7 $(11.8 \%)$ patients. Were available. The mean number of debridement was 3.4 (1-13). Colostomy was performed in $16(27.1 \%)$ of the patients, nd orchiectomy was performed in 6 (10.1\%). Vacuum Assisted Closure (VAC) was applied to eighteen patients (30.5\%). The average length of stay in the hospital was 15.4 (1-60) days. The average FGSI score of the patients was 4.16 (1-14), and the UFGSI score was 5.05 (116). Our mortality rate was $16.9 \%$.

DISCUSSION and CONCLUSION: Early diagnosis is very important in the diagnosis of Fournier's Gangrene. With early diagnosis, necessary surgical debridement, diversion procedure sandbroad-spectrum antibiotic applications increase the success rate of treatment.

Keywords: Fournier's gangrene, debridement, colostomy, diabetes mellitus

\section{GíRiş}

Fournier gangreni (FG) ilk olarak 1764 yılında Bauriene tarafından 45 yaşında bir ordu kasabında travmatik bir skrotal yaralanmaya bağlı 4 gün içinde hızla ilerleyen bir skrotal nekroz ile kendini gösteren klinik tablo olarak raporlanmış ve geniş debridmanlarla tedavi edilmiştir (1). Ancak hastalık Fransız zührevi bilimci Jean-Alfred
Fournier'in adı ile tariflenmiştir. Fournier 1883 'te 5 genç hastada skrotum ve penisin hızla ilerleyen gangrenöz nekrozunu dökümante edip hastalıkla alakalı da penis ve skrotumun "fulminan gangreni" terimini kullanmıştır (2-3).

Fournier gangreni deri altı arterlerin obliteratif endarteritleri ile karakterize edilen perine, skrotum ve penisin sinerjik polimikrobiyal 
gangrene enfeksiyonudur ve deri altı doku ve üstteki deride gangren ile sonuçlanır (4). Tüm yaş gruplarında ve her iki cinste de görülebilir. Yaş aralığı sıklıkla 55-65 yaş olup; erkeklerde kadınlardan 10 kat daha sıktır (5). Diabetes mellitus en yaygın risk faktörüdür. Tanısı genellikle klinik olarak konulur. Klinik bulgular ateş, titreme, bitkinlik ve sinsi lokal rahatsızlıktan ani başlangıçı şiddetli ağrı, ödem, eritem, endürasyon sonrası nekroz ve krepitasyon ile hızla kötüleşen bir klinik bulgulara kadar değişkenlik gösterebilir (6). Radyolojik inceleme, kliniği silik olgularda ve yayılımın derinliğini anlama konusunda faydalı olabilir. Bilgisayarlı Tomografi (BT) yüzeyel ve derin faysa yapılarını değerlendirerek birçok vakada fizik muayene ile tam olarak belirlenemeyen nekrozun derecesi hakkında cerrahi öncesi katkı sağlar (7). Nekroz sonrası ağrının azalması tipiktir. Çoğu olguda infeksiyon, aerob ve anaerob mikroorganizmaların birlikte hareket etmesiyle meydana gelir. Tanı konulan hastaların kültürlerinde ortalama 3 farklı bakteri türünün ürediği belirtilmektedir (8). Bu bakteriler toksin ve enzimleriyle nekroz yapar (9).

Fournier gangreni tedavisi, hastayı stabilize etmek için yoğun sıvı resüsitasyonunu ve varsa elektrolit dengesizliğinin düzeltilmesini içeren multimodal bir yaklaşıma dayanır (10). Bunu tüm nekrotik ve enfekte dokuları çıkarmak için kapsamlı debridmanlar ve rezeksiyonlar, geniş spektrumlu antibiyotikler ve gerektiğinde rekonstrüktif cerrahi takip eder. Vakum Aspirasyonlu Kapama (VAK) ve Hiperbarik Oksijen (HBO) de tedavide kullanılabilir. Fournier gangrenli hastalarda tıbbi bakım her ne kadar gelişmiş olsa da ortalama mortalite oranı \%3-45 arasındadır. Hastaların mortalite öngörülebilirliği için çeşitli şiddet skorlamaları geliştirilmişti. Ensık kullanılanlar Fournier Gangreni Şiddet İndeksi (FGSI) ve Uludağ Fournier Gangreni Şiddet Indeksidir (UFGSI) (11-12). Bu skorlama sistemlerine göre mortalite ve morbidite riski FGSI de 7 ve üzerinde, UFGSI de 9 ve üzerinde artmaktadır. Biz bu çalışmada FG nedeniyle opere ettiğimiz hastaların klinik veri ve tedavi sonuçlarını sunmayı amaçladık.

\section{GEREÇ ve YÖNTEMLER}

Merkezimizde Ocak 2010-Ağustos 2020 tarihleri arasında FG nedeniyle takip ve tedavi edilen hastaların dosyaları geriye dönük olarak incelendi. Hastaların tanıları fizik muayene yapılarak konulmuş olup; genital, perineal ve perianal bölgede hassasiyet, endurasyon, siyanoz, gangren ve cilt altı krepitasyon saptanan olgular FG olarak kabuledilmişti. Hastaların sıvı elektrolit resüstasyonları hızlıca düzenlenmiş, geniş spektrumlu antibiyotik tedavileri hemen başlanmış ve cerrahi debridmanları hızlıca yapılmıştı. Çoğu hastada debridman sayısı birden fazlaydı. Gerekliliği düşünülen hastalara da kolostomi, orşiektomi ve VAK uygulaması yapılmıştı. Çoklu veri eksiği olan hastalar ile cerrahi debridmanı başka merkezde yapılan hastalar çalışma dışı bırakıldı. Çalışmaya kriterleri tutan 59 hasta dahil edildi. Hastaların yaş, cinsiyet, hastane yatış süreleri, yandaş hastalıkları, cerrahi debridman sayıları, kolostomi, orşiektomi ve VAK yapılan hasta sayıları, yara kültür sonuçları, FGSI ve UFGSI değerleri ile mortalite bilgileri kaydedilip analiz edildi.

\section{BULGULAR}

Çalışmaya toplam 59 hasta dahil edildi. Bu hastaların 18 (\% 31)' i kadın, 41 (\% 69.)' i erkek idi. Yaş ortalaması 60 (34-87 aralığında) idi. Yayııım bölgesi olarak; hastaların 25 (\% 42,3)' inde skrotal, 27 (\% 45.76)' sinde perianal, 7 (\% 11,8)'inde vulvar bölgede hastalık bulgusu mevcuttu. Kırkdokuz hastada farklı sistemik hastalık tanıları [ Diabetes mellitus (DM), Hipertansiyon (HT), Kronik Obstrüktif Akciğer Hastalığı (KOAH), Malignite vb.] mevcuttu. Bunlardan 32 (\% 54,2) hastanın Diabetes mellitus tanısı mevcuttu. Bu hastaların 13 tanesinde DM tek yandaş hastalıktı. Oniki (\% 20,3) hasta onkolojik tanı almış ve takipleri yapılmaktaydı. Ortalama debridman 
sayısı 3.4 (1-13) idi. Onaltı (\% 27,11) hastaya diversiyon amaçlı kolostomi, 6 (\% 10.16) hastaya orşiektomi gerekliliği oldu. Onsekiz hastaya VAK uygulaması yapıldı. Hiperbarik oksijen tedavisi uygulanmadı. Hastanede ortalama yatış süresi 15 (1-60) gün idi. Mortalite oranımız \%16,9 idi.

Mortalite görülen hastalardan 7(\% 11.8)'si erkek, 3 (\% 5)'ü kadındı. Bunlardan 4 ü tarafımıza septik şok aşamasında gelmiş ve yatış süreleri sadece 1 gün olmuştur. Bu hasta grubunda yer alan vakaların 8 (\% 80)'i skrotal ve vulvar, 2 (\% 20)'i perianal kaynaklıydı ve yaş ortalamaları 66.4 (4686) idi. Mortalite grubunda yer alan hastaların debridman sayısı ortalaması toplam hasta ortalamasından farklı değildi. Hastane yatış süreleri ise ortalama 8.6 gün olup genel hasta ortalamasının altındaydı. Skorlama derecelerine bakıldında ise; UFGSI skor ortalamaları 7.8 (215), FGSI skor ortalamaları 7.7 (1-14)'idi.

Tablo 1. Hastaların Demografik Verileri

\begin{tabular}{|c|c|c|c|}
\hline & $\mathbf{N}$ & Median & $\%$ \\
\hline Toplam Hasta Sayısı & & 59 & \\
\hline \multicolumn{4}{|l|}{ Cinsiyet } \\
\hline Erkek & 41 & & 69 \\
\hline Kadın & 18 & & 31 \\
\hline Yaş & & $60(34-87)$ & \\
\hline \multicolumn{4}{|l|}{ Anatomik Lokalizasyon } \\
\hline Skrotal & 25 & & 42.3 \\
\hline Perianal & 19 & & 32.2 \\
\hline Vulvar & 7 & & 11.8 \\
\hline Pubis-Perine & 8 & & 13.5 \\
\hline Yatış Süresi & & 15 (1-60) gün & \\
\hline Debridman Sayısı & & $3.4(1-13)$ & \\
\hline Ostomi Yapılan Hasta & 16 & & 27.1 \\
\hline Orşiektomi Yapılan Hasta & 6 & & 10.1 \\
\hline Vacum Aspirated Closure & 18 & & 30.5 \\
\hline FGSI & & 7.7 & \\
\hline UFGSI & & 7.8 & \\
\hline \multicolumn{4}{|l|}{ Mortalite } \\
\hline Erkek & 7 & & 11.8 \\
\hline Kadın & 3 & & 5 \\
\hline
\end{tabular}

\section{TARTIŞMA}

Fournier gangreni yüksek mortalite ve morbidite ile seyreden, hızlı ilerleyen, anorektal, perineal ve genitoüriner bölgelerin süpüratif bakteriyel enfeksiyonudur. Subkütanöz damarların trombozisine yol açarak üzerindeki derinin gangreniyle sonlanan sinerjistik nekrotizan fasiitis halidir $(3,13)$. Nadir görülen bir durum olup eğer tanıda gecikme olursa mortalitesi yüksektir. Fournier gangreni, yılda 100.000 erkekte 1.6 vakada ortaya çıkar. Illerleyen yaş ile birlikte azalan immunite ve vasküler bozukluklar nedeniyle insidans ve mortalite artar. Kadın populasyonda nadir görülmesinin nedeni olarak; anatomik farklılık ileri sürülmüştür. Bizim çalışmamızda yaş ortalamamı 60 (34-87)'idi. Hastaların $41 \quad(\% 69,4)^{\prime}$ i erkek $18 \quad(\% 30,5)^{\prime} i$ kadındı. Erkek hasta sayımızın kadın hasta sayısından yüksek olması literatürle uyumlu olsa da erkek ve kadın oranı literatürden daha az idi.

Etyolojik faktörler arasında perineal, ürogenital ve anorektal bozuklukların yanı sıra bu bölgelerdeki cerrahi müdahaleler ve abdominal veya retroperitoneal enfeksiyonun yayılması 
nedeniyle de gelişebilir. Kadınlarda epizyotomi bölgesindeki enfeksiyonlar doğum sonrası dönemde de $F G^{\prime}$ ne neden olabilir. Birçok çalışma perianal enfeksiyonların $\mathrm{FG}^{\prime}$ de en yaygın etiyolojik faktör olduğunu göstermiştir $(8,13)$. Bizim çalışmamızda ise skrotal kaynaklı enfeksiyonlar çoğunluktaydı (\%42). Diabetes mellitus dahil bir dizi sistemik hastalık (vaskülopati, malignite, kronik alkolizm, siroz, böbrek yetmezliği vb.) FG için bilinen risk faktörleridir (14-15). Hipergliseminin hücresel bağışıklık üzerinde olumsuz etkileri vardır. Diyabetik hastalarda fagositik aktivite ve nötrofil disfonksiyonu olumsuz sonuçlara yol açar (4). Çalışmamızda 32 hastada DM mevcuttu. Bu 32 hastadan $8^{\prime}$ inde mortalite görüldü. Mortalite görülen hastalarımızın 7 tanesinin aynı zamanda $\mathrm{KOAH}, \mathrm{HT}$, Astım, Obezite gibi yandaş hastalık tanıları vardı.

Fournier gangreninin kliniği oldukça değişkendir. Lokal deri bulgularından sistemik sepsis tablosuna kadar farklı klinik tablolarda karşınıza çıkabilir. Bu nedenle perianal veya skrotal küçük bir yaradan bile FG gelişebileceği akıldan çıkarılmamalıdır. Deride lokal eritem, hiperemi, şişlik, kaşıntı gibi erken lezyonlar hızla ilerleme gösterip septik tabloyu ağırlaştırabilir. Muayenede krepitasyon varlığı \% 50 hastada mevcut olup gaz üreten bakteri varlığının en iyi kanıtıdır (9-10). Tanı koymada asıl yöntem fizik muayene olmasına rağmen radyolojik görüntüleme özel durumlarda tanıya yardımcı olmak ve tutulum yaygınlığını saptamak için kullanılır (13-14,16-17). Bilgisayarlı tomografi (BT) bulguları; asimetrik faciyal kalınlaşma, subkutanöz amfizem, sıvı toplanmaları ve apse formasyonudur (17). Subkutanöz amfizem her hastada rastlanmasa da önemli bir bulgudur. Bizim çalışmamızda da tanılar fizik muayene ile konulmuştu. Bilgisayarlı tomografi bulguları ile tutulum yaygınlığı saptanmıştı (Resim1). Çalışmamızdaki mortalite görülen hastaların 4 ünde hastane başvuruşlarında septik şok tablosu mevcuttu. Bu hastalarda erken tanı ve tedavide gecikme olmasına bağlı mortalite olduğunu düşünmekteyiz.

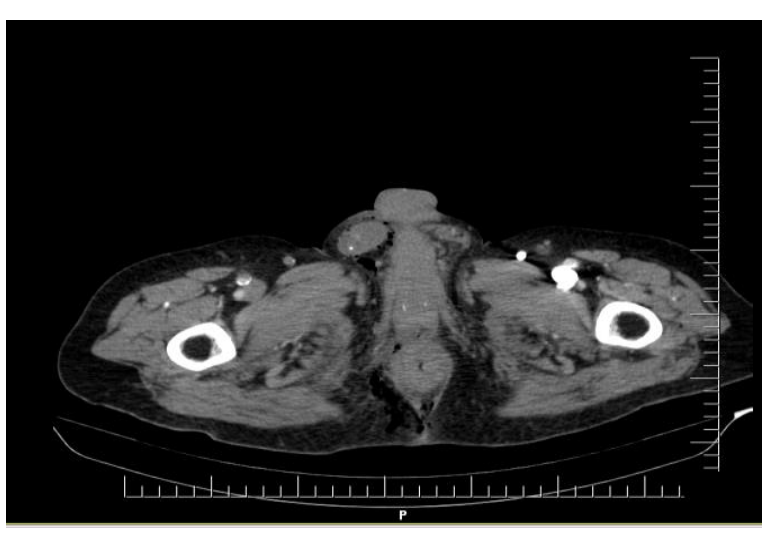

Resim 1. Skrotum, anal bölge kas planları ve pelvik bölgede yaygın hava dansiteleri

Fournier gangreni ayırıcı tanısı önemlidir. Testis ödemi, testis apsesi, skrotal apse, perianal apse, vaskülit, selülit gibi birçok patolojiyle karışabilir. Tanının erken konması tedavide önem arzettiğinden gereğinde ileri tetkik ile tanı netleştirilmelidir. Yapılan cerrahi müdahale esnasında alınacak doku örneğinde nekroz, konjesyon, mikroabse odakları ve damar yatağında enflamasyon görülmesi tanıyı netleştirir. Bizim çalışmamızda da tüm hastaların debridman doku örneklemeleri patolojik olarak incelenmiş ve aynı bulgulara rastlanmıştı.

Tedavinin ana prensipleri, hemodinamik stabilizasyon, parenteral geniş spektrumlu antibiyotikler ve acil cerrahi debridmandır (1314). Ancak en etkin aşama cerrahi debridman aşamasıdır. Canlı dokulara ulaşılana kadar debridmana devam edilmelidir. Her 24-48 saatte pansuman kontrol edilip gereğinde debridman tekrarlanmalıdır. Cerrahi debridmanın amacı tüm ölü dokuları çıkartıp, toksisiteyi azaltarak enfeksiyonun ilerlemesini durdurmaktır $(3,13)$. Literatürlerde ortalama debridman sayısının 3.5 olduğu bildirilmiştir (13). Hastaya ait komorbiditeler, cerrahın ve merkezin bu konudaki tecrübeleri, tanıda gecikme gibi çok faktörlü değişkenler debridman sayısını etkileyebilmekte ve tedavi planı değişebilmektedir. Bu nedenle debridman sayısı ve uygulanan tedavi seçeneklerini standartize 
etmek zordur. Bizim çalışmamızda da ortalama debridman sayımız 3.4 (1-13) idi.

Fournier gangreninde etken, mikroorganizmaların karışımıdır. Kan kültürleri genellikle negatiftir. Bakteriyel organizmalar arasında Enterobakteriler özellikle de Escherichia coli kültürde ensık üreyen organizmalardır. Ardından Gr (+) koklar gelir (18-19). Çalışma kapsamındaki hastaların kültürlerinde de aynı türlerin kolonize olduğu rapor edilmişti. Ampirik ve terapötik/spesifik çoklu antibiyoterapi bu mikroorganizmalara göre düzenlenmişti.

Fekal diversiyon FG takibinde yarayı kontaminasyondan korumak için gerekebilir. Geniş perine yaralarında ve sfinkter problemli hastalarda kolostomi tercihi iyileşmede yarar sağlar (10). Ciddi gaita bulaş riski olan 16 (\% $27,11)$ hastamızda kolostomi tercihi yapılmıştı. Ayrıca testis ve penis kanlanma bozukluğu olan 1 (\% 1,69) hastaya penektomi,6 (\% 10) hastaya da orşiektomi (1 tanesi bilateral) yapılmıştı.

Fournier gangreninde yara iyileşmesinde etkili olduğu gösterilen bir takım tedavi yöntemleri de literatürde bildirilmiştir. Optimal doku oksijenizasyonu sağlayan HBO tedavisi bunlardan biridir (20). Bir diğer etkili tedavi yöntemi de VAK uygulamasıdır (20). Nemli, inflame, ödemli ve enfekte alana uygulanan negatif basınç yaradaki eksudanın etkili ve başarılı bir şekilde aspire edilmesini sağlar. Ayrıca anjiogenezi uyarır, hücre proliferasyonunu hızlandırır ve fibroblast migrasyonunu arttırır. Yarayı tamamen kaplayarak bakteriyel kontaminasyonu engeller ve yarayı korur. Vakum Aspirasyonlu Kapama ve HBO tedavisi kombine kullanıdığında ödem ve interstisyel basınç azalması HBO etkinliğini arttıır (21-22). Merkezimizde HBO ünitesi bulunmadığından hastalarımıza bu tedavi yöntemi uygulanmamıştı. Onsekiz hastaya ise yara uygunluklarına göre VAC tedavisi yapılmıştı.

Hastaların hastanede kalış süreleri çok faktörlü bileşenlerden etkilenir. Yara genişliği, anatomik lokalizasyonu, komorbidite varlığı, skorlama derecesi, merkezin deneyimi ve ekipmanı bu faktörlerden bazılarıdır. Bu faktörler hasta kliniğindeki seyri değiştirebildiğinden literatürde farklı merkezlerde farklı yatış süreleri belirtilmiştir. Bizim çalışmamızda ortalama hastane yatı̧s süremiz 15 (1-60) gün idi.

Fournier gangreninin önem derecesini tahmin etmek için şiddet indeksi puanlama skorları geliştirilmiştir. Bunların ilki olan FGSI; Laor ve arkadaşları tarafından 1995' te geliştirilmiş (11), 2010 yılında da Yılmazlar ve arkadaşları tarafından ise UFGSI tariflenmiştir (12). FGSI ve UFGSI en yaygın kullanılan ve kabul görmüş şiddet skalalarıdır. UFGSI; FGSI' ine yaş skoru ve enfeksiyon yaygınlık skoru eklenerek oluşturulmuştur. Fournier gangreninde mortalite ve morbidite öngörülebilirliği konusundaki UFGSI ve FGSI skorları, her ne kadar duyarlılık ve özgüllük konusundaki oranları mevcut çalışmalarda yüksek çıksa da her iki skorlama sistemi de oldukça karmaşıktır. Karmaşıklıkları nedeniyle de klinik uygulamalarda pratik olmaktan uzaktır. Enfeksiyon yaygınlık skorunu enfeksiyonu lokalize ederek düşük düzeyde tutmak ve mortaliteyi önlemek mümkündür. UFGSI skoru 9 ve üzeri, FGSI skoru 7 ve üzerinde olunca mortalite ve morbidite oranı artmaktadır. Bizim çalışmamızda da mortal seyreden 10 vakanın; 3' ünde UFGSI 9 ve üzerinde, 5 vakada FGSI 7 ve üzerindeydi. Toplamda ise 11 hastanın FGSI değeri 7 ve üzerinde, 10 hastanın UFGSI değeri de 9 ve üzerindeydi. Yani FGSI ya göre yüksek riskli 11 hastanın 5' i, UFGSI ya göre de 10 hastanın 3' ünde mortalite görülmüştü. Bu skorların güvenilirlik oranları farklı çalışmalarda yüksek gösterilmiş olsa da bizim çalışmamızda bu oran düşük seyretmiş ve mortalite oranları skorlama ölçütlerine göre daha düşük bulunmuştur. Bunda erken ve etkili debridman ve multidisipliner, özenli resüstasyonun etkili olduğunu düşünüyoruz. Fournier gangreninde mortalite oranı \%3-45 arasındadır. Bizim çalışmamızdaki mortalite oranı ise $\% 16,9$ idi. Tarafımıza septik tabloda başvuran 4 hastada mortalite görülmüş ve bu durum mortalite 
oranımızda artışa neden olmuştur. Hastanemiz bölgede referans hastane olup azımsanmayacak sayıda terminal dönem hasta tarafımıza yönlendirilmektedir. $\mathrm{Bu}$ da morbidite ve mortalite oranlarımızı göreceli olarak yükseltmektedir.

Çalışmamızın azımsanmıyacak sayıda hasta içermesi nedeniyle literatüre katkı sağlayacağını düşünmekle beraber retrospektif bir çalışma olması ve kontrol grubu içermemesi nedeniyle kısıtlılık içerdiğini düşünmekteyiz.

\section{SONUÇ}

Fournier gangreni her ne kadar son zamanlarda tanı, takip ve tedavi olanakları artmış olsa da yüksek mortalite oranlarına sahip bir hastalıktır. Erken tanı, yüz güldürücü sonuç almada en önemli faktördür. Cerrahi debridman, geniş spektrumlu ampirik antibiyoterapi, uygun sIVı replasmanı ve hemodinamik destek ile birlikte gerekli vakalarda uygulanan koruyucu kolostomi, HBO ve VAK uygulamaları ve rekonstüriktif cerrahiyi içeren çok basamaklı ve agresif tedavi yöntemi FG tedavisinde etkin ve faydalı olmaktadır. Multidisipliner tedavi yaklaşımı ile FG' li hastalarda morbidite ve mortalite azaltılabilmektedir. Erken tanı ve tedavi ile birlikte klinik gözlem, tecrübe ve ekipman tedavi sonuçlarının iyileştirilmesinde önemli faktörlerdir.

Etik Kurul Onayı: Bu çalışma Başkent Üniversitesi Tıp ve Sağıık Bilimleri Araştırma Kurulu tarafından onaylanmıştır.

Bilgilendirilmiş Onam: Katılımcılardan yazılı onam alınmıştır.

Çıkar Çatışması: Yazarlar çıkar çatışması beyan etmemişlerdir.

Finansal Destek: Başkent Üniversitesi Araştırma Fonunca Desteklenmiştir.

\section{KAYNAKLAR}

1. Bauriene $\mathrm{H}$ : Sur uneplaiequis'estterminee par la sphacele de la scrotum. J. gén. de méd., chir. et pharm, 1764; 20: 251-56.

2. Fournier JA: Gangrene foudroyante de la verge. Sem Méd Prof Med Soc, 1883; 4: 589-97.

3. Eke N. Fournier's gangrene: a review of 1726 cases, $\mathrm{Br}$ J Surg, 2000; 87(6): 718-28.

4. Korkut M, Icoz G, Dayangac M, et al. Outcomeanalysis in patients with Fournier's gangrene. Report of 45 cases. Dis Colon Rectum ,2003; 46 (5): 649-52.

5. Hamdy, Freddie C; Eardley, Ian. Oxford Textbook of Urological Surgery. Oxford University Press.p. 76,2017.

6. Consten EC, Slors JFM, Danner SA et al. Severe complications of perianalsepsis in patients with human immunodeficiency virus, Br J Surg 1996; 83(6): 778-80.

7. Levenson RB, Singh AK, Novelline RA. Fournier gangrene: role of imaging. Radiographics. 2008 MarApr;28(2): 519-28.

8. Morpurgo E, Galandiuk S. Fournier's gangrene. Surg Clin North Am. 2002 Dec;82(6): 1213-24.

9. Yılmazlar T: Fournier Gangreni. In: Anorektal Bölgenin Selim Hastalıkları, Edt. Menteş, Bulut, Alabaz, Leventoğlu,2011; Sayfa: 267-77.

10. Smith GL, Bunker CB, Dinneen MD. Fournier's gangrene. Br J Urol. $1998 \mathrm{Mar}$;81(3): 347-55.

11. Laor E, Palmer LS, Tolia BM. Outcome prediction in patients with Fournier'sgangrene. J Urol 1995; 154: 8992.

12. Yılmazlar T, Ozturk E, Ozguc H, et al. Fournier's gangrene: an analysis of 80 patients and a novel scoring system. Tech Coloproctol 2010; 14: 217-23.

13. Mallikarjuna MN, Vijayakumar A, Patil VS et al. Fournier's gangrene: Current Practices. ISRN Surg 2012: 937-42.

14. Benjelloun EB, Souiki T, Yakla N et al. Fournier's gangrene: our experience with 50 patient sand analysis of factor saffecting mortality. World J Emerg Surg 2013; 8-13.

15. Yılmazlar T, Isık O, Ozturk E et al. Fournier's gangrene: Review of 120 patients and predictors of mortality. Ulus Travma Acil Cerrahi Derg 2014; 20: 333-7.

16. Heiner JD, Baldwin K, Laselle B. Fournier gangrene: rapid diagnosis with bedside ultrasonography. CJEM 2010; 12: 528-9.

17. Levenson RB, Singh AK, Novelline RA. Fournier gangrene: role of imaging. Radiographics 2008; 28: 519-28.

18. Morpurgo E, Galandiuk S. Fourniers Gangrene. SurgClin North Am 2002; 82(6): 1213-24.

19. Jallali N, Witney S, Butler PE. Hyperbaricoxyjen as adjuvant therapy in the manangment of necrotizing faciitis. Am J Surg 2005; 189: 462-6.

20. Olsofka JN, Carrillo EH, Spain DA et al. The continuing challenge of fournier's gangrene in the 1990s. Am Surg 1999; 65: 1156-9. 
Erkan S. ve Ark.

21. Pastore AL, Palleschi G, Ripoli A, et al. A multistep approach to manage Fournier's gangrene in a patient with unknown type II diabetes: surgery, hyperbaric oxygen, and vacuum-assisted closure therapy: a case report. J Med Case Rep 2013; 3; 7.

22. Sökmen S. Fournier Gangreni. ANKEM Derg 2012; 26: 331- 336. 